\title{
Differential recognition of the left vs. the right side of human faces
}

\author{
DARLENE KENNEDY, DENISE BEARD, and W. J. CARR \\ Beaver College, Glenside, Pennsylvania 19038
}

\begin{abstract}
Ninety-one college students inspected six adult male faces (frontal view) for $5 \mathrm{~min}$, with the instruction to remember each face. In a recognition test conducted 1 week later, they attempted to identify the six faces seen previously from a group of 12 adult male faces. During the test, three independent groups ( $n=30-31 / g r o u p)$ saw the full faces, only the left side, or only the right side of each face. The subjects viewing full faces during the recognition test committed reliably fewer errors $(p<.001)$ than those viewing either half of the faces. Further, those viewing the left side committed reliably fewer errors $(p<.05)$ than those viewing the right side. The left side of a face either contains more cues mediating individual recognition or, more likely, evokes more efficient central processing than does the right side.
\end{abstract}

Appropriate interactions among members of a group require that they perceive and respond to each other as individuals as well as members of subgroups (e.g., malefemale, child-adult, etc.). Individual recognition is mediated largely by the unique configuration of each person's face, and humans are quite adept at recognizing faces that they have seen before, despite changes in faces with age, orientation, or emotional state (Gombrich, 1961; Scapinello \& Yarmey, 1970; Warr \& Knapper, 1968).

The present research was designed to identify the cues that enable humans to recognize faces that they have seen before. Intuitively, it seems likely that different parts of the face convey varying amounts of information (i.e., discriminative stimuli) by which faces are recognized. Indirect evidence for this view stems from the fact that the Identi-Kit, used widely by law enforcement agencies to make copies of almost any human face, contains 102 different sets of eyes, but only 40 sets of lips. Presumably, people differ more with respect to the configuration of their eyes than of their lips. Stated differently, specifying a person's eyes requires more information than specifying a person's lips.

Goldstein and Mackenberg (1966) provided more direct evidence of the hypothesis that different parts of the face convey varying amounts of information concerning a person's identity. They showed that the upper half of the face serves as a better cue for recognition of a full face seen previously than does the lower half and that the left half of the face serves approximately as well as the upper half. Goldstein and Mackenberg did not compare the left side vs. the right side of the face, perhaps because they thought of the two sides as being functionally equivalent.

We thank William Barker, Jean Carr, and Steven Gulkus for technical assistance. Requests for reprints should be sent to W. J. Carr, Department of Psychology, Beaver College, Glenside, Pennsylvania 19038.
More recent evidence indicates that the human face is not bilaterally symmetrical and that the right side resembles the whole face more closely than does the left side (Gilbert \& Bakan, 1973; Sackheim, Gur, \& Saucy, 1978; Marquette, Note 1). Therefore, the present experiment was conducted to determine whether subjects differ in their ability to recognize faces as having been seen before or not, depending on the cues available during the recognition test (i.e., full face, left side of the face, or right side of the face). As used here, the term "left side" refers to that part of a person's face that is on the observer's right as the observer faces the person.

One might reasonably expect that full faces would be recognized best, because they contain the same amount of information as was present during previous inspection. But subjects may also differ in the ability to recognize the left vs. the right side of faces. If so, such a difference must stem either from varying amounts of information actually contained in the two sides or from varying amounts of central processing evoked by the two sides of the faces during inspection and/or testing (Gilbert \& Bakan, 1973).

\section{METHOD}

Subjects

Ninety-one college students ( 82 females and 9 males) viewed six full faces during inspection. The subjects were then randomly assigned to one of three groups ( $n=30-31$ /group), differing only with respect to the aspect of the faces presented 1 week later during a recognition test (i.e., full face, left side, or right side). Prior to the experiment, the subjects had not seen any of the faces that were presented.

\section{Materials}

The faces used in the present experiment were the same as those prepared by Cohen and Carr (1975). Twelve photographs of adult male faces (frontal view) were selected randomly from a large pool of photographs. The photographs were of males aged $22-40$ years, displaying no emotion (e.g., no smiles or frowns) and possessing no unusual features, such as scars, beards, or 
eyeglasses. The 12 photographs were converted to standardized line drawings via the Identi-Kit (Smith-Wesson Law Enforcement Group, Santa Ana, California). Copies were made of six of the full faces arranged on a single sheet of paper (the inspection sheet), and copies were made of all 12 faces on the test sheet. Test sheets were of three types: full face, left side of face, or right side of face.

\section{Procedure}

During the inspection phase of the experiment, each subject viewed an inspection sheet containing the six full faces for $5 \mathrm{~min}$ in groups of 10-25, with the instruction to remember the faces but not to discuss the experiment with others. One week later, approximately one-third of each group was presented with one of the three types of test sheet (full face, left side of face, or right side of face) containing 12 faces and was asked to identify the six faces seen during the previous inspection, guessing as necessary. No time limit was imposed on the recognition test.

\section{RESULTS AND DISCUSSION}

The experimenters recorded the number of errors committed by each subject during the recognition test, an error being defined as an omission, that is, a failure to identify a face that had been presented during previous inspection. Because each subject was required to identify exactly six faces during the test, an error of omission automatically produced a compensating error of commission (false positive), but only errors of omission were counted.

Despite the brief inspection period $(5 \mathrm{~min})$ and the 1-week interval between inspection and the recognition test, the 91 subjects proved to be quite capable of discriminating between those faces that had been seen before and those that had not been seen before. The overall error rate was only $8.4 \%$ (i.e., only 46 errors were made of the possible 546 responses).

The important issue is the effect of the type of cues available during the recognition test upon the number of errors committed. The subjects viewing the full faces, left side of faces, and right side of faces committed 6 , 16 , and 33 errors, respectively. Overall, the three groups differed reliably [Kruskal-Wallis one-way ANOVA, $\mathrm{H}(2)=11.94, \mathrm{p}<.01]$. Moreover, the subjects viewing full faces during the recognition test committed reliably fewer errors than those viewing the left side (MannWhitney $\mathrm{U}$ test, $\mathrm{z}=3.80, \mathrm{p}<.001)$ and those viewing the right side $(z=2.14, p<.05)$. Finally, the subjects viewing the left side committed reliably fewer errors than those viewing the right side $(\mathrm{z}=2.12, \mathrm{p}<.05)$. Therefore, we conclude that relative to the right side, the left side of a face either contains more information by which humans can be recognized as individuals or, more likely, evokes more efficient central processing during the inspection and/or recognition test.

The present findings are inconsistent with those of Geffen, Bradshaw, and Wallace (1971), who reported that information from the right side of the face is processed more efficiently by observers than information from the left side, especially in tasks involving easy discriminations made over relatively short periods of time. A possible resolution of this inconsistency has been proposed by Patterson and Bradshaw (1976), who showed that difficult facial discriminations involving long-term memory storage are processed more efficiently by the left cerebral hemisphere (right visual field) and that easy discriminations involving shortterm memory are processed more efficiently by the right hemisphere (left visual field).

\section{REFERENCE NOTE}

1. Marquette, A. Structural asymmetry of the face. Paper presented at the meeting of the Eastern Psychological Association, Baltimore, Maryland, April 1982.

\section{REFERENCES}

Cohen, M. E., \& Carr, W. J. Facial recognition and the von Restorff effect. Bulletin of the Psychonomic Society, 1975, 6, 383-384.

Geffen, G., Bradshaw, J. L., \& Wallace, G. Interhemispheric effects on reaction time to verbal and nonverbal visual stimuli. Journal of Experimental Psychology, 1971, 87, 415-422.

Gilbert, C., \& Bakan, P. Visual asymmetry in perception of faces. Neuropsychologia, 1973, 11, 355-362.

Goldstein, A. G., \& Mackenberg, E. J. Recognition of human faces from isolated facial features: A developmental study. Psychonomic Science, 1966, 6, 149-150.

Gombrich, E. H. Art and illusion. New York: Pantheon, 1961.

Patterson, K., \& Bradshaw, J. L. Differential hemispheric mediation of nonverbal visual stimuli. Journal of Experimental Psychology: Human Perception and Performance, 1976, 2, 246252.

Sackheim, H. A., Gur, R. C., \& Saucy, M. C. Emotions are expressed more intensely on the left side of the face. Science, 1978, 202, 434-435.

Scapinello, K. F., \& YarmeY, A. D. The role of familiarity and orientation in immediate and delayed recognition of pictorial stimuli. Psychonomic Science, 1970, 21, 329-330.

WARR, R. B., \& KNAPPER, C. The perception of people and events. New York: Wiley, 1968.

(Received for publication June 16, 1982.) 